\title{
Vitamin D and depression in geriatric primary care patients
}

\author{
This article was published in the following Dove Press journal: \\ Clinical Interventions in Aging \\ 2 May 2013 \\ Number of times this article has been viewed
}

\author{
Maria I Lapid' \\ Stephen S Cha ${ }^{2}$ \\ Paul Y Takahashi ${ }^{3}$ \\ 'Division of Outpatient Consultation, \\ Department of Psychiatry and \\ Psychology, ${ }^{2}$ Division of Biomedical \\ Statistics and Informatics, Department \\ of Health Sciences Research, ${ }^{3}$ Division \\ of Primary Care Internal Medicine, \\ Department of Medicine, Mayo Clinic, \\ Rochester, Minnesota, USA
}

Correspondence: Maria I Lapid Department of Psychiatry and Psychology, Mayo Clinic, 200 First Street SW, Rochester, MN 55905, USA

$\mathrm{Tel}+\mathrm{I} 5072844$ I59

Fax + I 5072844158

Email lapid.maria@mayo.edu
Purpose: Vitamin D deficiency is common in the elderly. Vitamin D deficiency may affect the mood of people who are deficient. We investigated vitamin D status in older primary care patients and explored associations with depression.

Patients and methods: A cross-sectional study was conducted and association analyses were performed. Primary care patients at a single academic medical center who were $\geq 60$ years with serum total 25-hydroxyvitamin D (25[OH]D) levels were included in the analysis. The primary outcome was a diagnosis of depression. Frailty scores and medical comorbidity burden scores were collected as predictors.

Results: There were 1618 patients with a mean age of 73.8 years $( \pm 8.48)$. The majority $(81 \%)$ had optimal ( $\geq 25 \mathrm{ng} / \mathrm{mL}) 25(\mathrm{OH}) \mathrm{D}$ range, but $17 \%$ met mild-moderate $(10-24 \mathrm{ng} / \mathrm{mL})$ and $3 \%$ met severe $(<10 \mathrm{ng} / \mathrm{mL})$ deficiencies. Those with severe deficiency were older $(P<0.001)$, more frail $(P<0.001)$, had higher medical comorbidity burden $(P<0.001)$, and more frequent depression $(P=0.013)$. The $694(43 \%)$ with depression had a lower 25(OH)D than the nondepressed group (32.7 vs $35.0, P=0.002)$. 25(OH)D was negatively correlated with age $(\mathrm{r}=-0.070, P=0.005)$, frailty $(\mathrm{r}=-0.113, P<0.001)$, and medical comorbidity burden $(\mathrm{r}=-0.101, P<0.001)$. A 25(OH)D level was correlated with depression (odds ratio $=0.990$ and $95 \%$ confidence interval $[\mathrm{CI}]=0.983-0.998, P=0.012$ ). Those with severe vitamin $\mathrm{D}$ deficiency were twice as likely to have depression (odds ratio $=2.093$ with 95\% CI 1.092-4.011, $P=0.026)$.

Conclusion: Vitamin D deficiency was present in a fifth of this older primary care population. Lower vitamin D levels were associated with depression. Those with severe deficiency were older and more likely had depression.

Keywords: elderly, frailty, hydroxyvitamin D, mood

\section{Introduction}

Vitamin D deficiency is an important condition, with clinical implications stretching from skeletal and neuromuscular functions to extraskeletal health such as cancer, cardiovascular disease, multiple sclerosis, psoriasis, diabetes, and other diseases such as schizophrenia and depression. ${ }^{1,2}$ Falls and strength are also hallmark associations with vitamin D. ${ }^{3}$ Despite its importance in overall health, vitamin D insufficiency and deficiency are still very common in the USA. This may be the result of changes in time outdoors or changes in dietary habits. The definitions of optimal, insufficient, and deficient vitamin D levels vary in the literature. The Institute of Medicine defined total serum 25-hydroxyvitamin D (25[OH]D) $\geq 20 \mathrm{ng} / \mathrm{mL}$ as optimal, $12-19 \mathrm{ng} / \mathrm{mL}$ as inadequate, and $<12 \mathrm{ng} / \mathrm{mL}$ as deficient. ${ }^{4}$ The Endocrine Society guideline definitions 
were higher, ie, $25(\mathrm{OH}) \mathrm{D}$ was optimal if $\geq 30 \mathrm{ng} / \mathrm{mL}$, insufficient if $21-29 \mathrm{ng} / \mathrm{mL}$, and deficient if $\leq 20 \mathrm{ng} / \mathrm{mL} .^{5}$ As a consequence of varied definitions, the prevalence of vitamin $\mathrm{D}$ deficiency varies as well, ranging from $25 \%$ to $50 \%$ in typical patients, ${ }^{6}$ to $60 \%$ in a group of psychiatric inpatients, ${ }^{7}$ and even higher in hospitalized patients, from $57 \%^{8}$ to $74 \%{ }^{9}$ in general medical inpatients.

Vitamin D deficiency has been implicated in depression, although studies have shown mixed results. In the elderly, positive association studies have demonstrated hypovitaminosis D as a risk factor for depression in population-based cohorts. ${ }^{10-14}$ On the other hand, other studies report conflicting findings. A large study $(n=3916)$ that investigated the relationship between vitamin $\mathrm{D}$, parathyroid hormone, and depression in United States adults aged 20 or older did not find any relationship between hypovitaminosis D and depression, further confirmed in a subanalysis of geriatric patients. ${ }^{15}$ In a study of psychiatric groups with schizophrenia, alcohol addiction, and major depression, levels of vitamin D were lower than those of normal controls but not different between the psychiatric groups. ${ }^{16}$ One study on the effects of vitamin D supplementation on depression in overweight/ obese patients (aged 21-70 years) found that at baseline there was no correlation between vitamin $\mathrm{D}$ and depression scores, although the authors did find improvement of depression scores all measured by the Beck Depression Inventory in those randomized to vitamin D supplementation. ${ }^{17}$

In an effort to find clarity amid the inconclusive evidence on the relationship between vitamin $\mathrm{D}$ and depression, we conducted a cross-sectional study to investigate the vitamin D status of geriatric patients seen in the primary care setting and explore whether any associations exist between vitamin D levels and depression. We anticipated that lower vitamin D levels would be associated with a diagnosis of depression. Our study was unique in our ability to look at additional correlates including frailty measures and burden of medical comorbidity.

\section{Materials and methods Design}

This study included empaneled primary care patients at a single academic medical center. The study retrospectively evaluated records from 2004-2008. This was an Institutional Review Board (IRB)-approved cross-sectional study of patients aged 60 years and older seen in the primary care internal medicine practice.

\section{Participants}

The subjects were adults over age 60 with an assigned primary care physician with family medicine or primary care internal medicine within Mayo Clinic in Rochester, Minnesota, USA. Participants were included if they had one serum 25(OH)D level.

\section{Exclusion criteria}

Subjects who refused a medical record review were excluded from the study. Those participants without a 25(OH)D level were also excluded.

\section{Outcome variables}

The primary outcome variable was the clinical diagnosis of depression. We collected electronic data on depression diagnosis from the Hospital International Classification of Disease Adaptation (HICDA) codes for depression and other mood disorders, which is a coding system developed and used at Mayo Clinic that is an adaptation of ICD-8. It uses an "autocoder" to automate the coding process with a computerized system, and assigns HICDA codes to all word-based diagnoses in the clinical notes of the Mayo Clinic electronic medical record. ${ }^{18}$ A single person may have more than one depression-related diagnosis on the same or different visits. The diagnosis of depression was made clinically by the clinical medical providers in either primary or specialty care.

\section{Predictor variables}

The primary predictor variable was the vitamin D level and the diagnosis of vitamin D deficiency. Records were electronically identified by searching institutional clinical databases for geriatric patients seen in primary care internal medicine from 2005-2006 who had at least one total serum 25(OH)D level from 2004-2008. For those with multiple serum $25(\mathrm{OH}) \mathrm{D}$ measurements, we used the index or first measurement. Levels of $25(\mathrm{OH}) \mathrm{D}$ were grouped into optimal range (at least $25 \mathrm{ng} / \mathrm{mL}$ ), mild to moderate deficiency (10-24 ng/mL), and severe deficiency $(<10 \mathrm{ng} / \mathrm{mL})$ as established by Mayo Medical Laboratories (http://www. mayomedicallaboratories.com), where all 25(OH)D measurements are made by liquid chromatography-tandem mass spectrometry and total serum $25(\mathrm{OH}) \mathrm{D}$ assessed as the additive sum of $25(\mathrm{OH}) \mathrm{D} 2$ and $25(\mathrm{OH}) \mathrm{D} 3$ components.

Two other major covariables included frailty as measured by the Elder Risk Assessment (ERA) index and age. ERA scores used to identify frail individuals were collected electronically. ERA is an instrument that measures the potential risk for hospitalization or emergency room visit. The predictors in the ERA include age, gender, number of hospital days, and medical comorbidities based on 
administrative data. ${ }^{19}$ The ERA predicts functional disability as measured by nursing home placement. ${ }^{20}$ The ERA can provide some adjustment for functional disability and comorbid health conditions.

Medical comorbidity was measured using the Charlson Comorbidity Index (CCI). ${ }^{21}$ The CCI accounts for most medical comorbidities and is widely used as a validated prognostic indicator. ${ }^{22}$ Scores range from 0 to 40 and higher scores predict mortality. The CCI was scored electronically using the diagnoses in the institution's medical index database.

\section{Study size}

This was an initial pilot study, and we used all available data for analysis within the time period described.

\section{Data analysis}

Patient demographic characteristics were summarized by either mean \pm standard deviation (SD) for continuous data, or frequency (percentage \%) for proportional (dichotomous) data. Pearson correlation coefficient, two sample $t$-test, oneway analysis of variance (ANOVA), and multivariate logistic model analyses were performed. $P$ values less than 0.05 were considered statistically significant. All statistical analyses were handled by SAS 9.3 software (SAS institute Inc, Cary, NC).

\section{Results}

\section{Demographic and clinical characteristics}

There were 12,650 geriatric patients 60 years and older who were seen in primary care internal medicine from 2005 to 2006 , of which 1618 patients had at least one 25(OH)D measurement between 2004 and 2008. The distribution of $25(\mathrm{OH}) \mathrm{D}$ categories is summarized in Table 1 , which shows the majority in the optimal range $(81 \%)$, although a small percentage met the criteria for mild-moderate deficiency $(17 \%)$ and severe deficiency (3\%). At the time of the first $25(\mathrm{OH}) \mathrm{D}$ measurement, subjects had a mean age of 73.8 ( \pm 8.48 , range $60-101)$ and the majority were female (75\%). Mean scores for ERA and CCI were 6.51 \pm 6.48 and $4.09 \pm 3.76$, respectively.

\section{Depression}

It was common to find depression in this cohort: 694 (43\%) carried a depression diagnosis, with the severe vitamin D deficiency group having a higher frequency of depression $(P=0.013$, Table 1). A single person may have more than one depression-related diagnosis on the same or different visits. The most common diagnosis at the first occurrence was depression not otherwise specified (NOS) (89.9\%); other less common diagnoses include recurrent depression, dysthymic disorder, bipolar disease, psychotic depression NOS, and affective disorder NOS.

\section{Gender analysis}

Females had lower rates of $25(\mathrm{OH}) \mathrm{D}$ deficiencies than males $(P<0.001)$, which was proportional in this cohort, with three times more females than males (Table 1). Females showed the same trend as the combined group with respect to those with severe deficiency having more

Table I Distribution of vitamin D levels and other patient characteristics

\begin{tabular}{|c|c|c|c|c|c|c|c|c|c|c|c|c|c|}
\hline & \multicolumn{3}{|c|}{ Overall } & \multicolumn{3}{|c|}{$\begin{array}{l}\text { Optimal } \\
\text { range }\end{array}$} & \multicolumn{3}{|c|}{$\begin{array}{l}\text { Mild-moderate } \\
\text { deficiency }\end{array}$} & \multicolumn{3}{|c|}{$\begin{array}{l}\text { Severe } \\
\text { deficiency }\end{array}$} & \multirow[t]{2}{*}{$P$-value } \\
\hline & $\mathbf{N}$ & SD & $\%$ & $\mathbf{N}$ & SD & $\%$ & $\mathbf{N}$ & SD & $\%$ & $\mathbf{N}$ & SD & $\%$ & \\
\hline All & 1,618 & & & $\mathrm{I}, 307$ & & 81 & 269 & & 17 & 42 & & 3 & \\
\hline Age & 73.8 & \pm 8.48 & & 73.33 & \pm 8.29 & & 75.58 & \pm 9.02 & & 76.6 & \pm 8.86 & & $<0.001$ \\
\hline ERA score & 6.51 & \pm 6.48 & & 5.95 & \pm 6.24 & & 8.68 & \pm 6.97 & & 10.19 & \pm 6.82 & & $<0.001$ \\
\hline $\mathrm{CCl}$ score & 4.09 & \pm 3.76 & & 3.78 & \pm 3.62 & & 5.22 & \pm 4.03 & & 6.6 & \pm 4.12 & & $<0.001$ \\
\hline Depression $^{\mathrm{a}}$ & 694 & & 43 & 547 & & 42 & 120 & & 45 & 27 & & 64 & 0.013 \\
\hline Females & 1,213 & & 75 & 1,016 & & 84 & 168 & & 14 & 29 & & 2 & \\
\hline Age & 73.7 & \pm 8.60 & & 73.34 & $\pm 8.4 \mathrm{I}$ & & 75.53 & \pm 9.30 & & 77.38 & \pm 9.12 & & $<0.001$ \\
\hline ERA score & 6.05 & \pm 6.37 & & 5.64 & \pm 6.18 & & 7.83 & \pm 6.88 & & 10.24 & \pm 6.71 & & $<0.001$ \\
\hline $\mathrm{CCl}$ score & 3.54 & \pm 3.50 & & 3.27 & \pm 3.30 & & 4.58 & \pm 4.01 & & 6.76 & \pm 4.58 & & $<0.001$ \\
\hline Depression & 525 & & 43 & 427 & & 42 & 79 & & 47 & 19 & & 66 & 0.024 \\
\hline Males & 405 & & & 291 & & & 101 & & & 13 & & & \\
\hline Age & 74 & \pm 8.10 & & 73.31 & \pm 7.85 & & 75.67 & \pm 8.58 & & 74.85 & \pm 8.34 & & 0.038 \\
\hline ERA score & 7.89 & \pm 6.63 & & 7.03 & \pm 6.31 & & 10.09 & \pm 6.92 & & 10.08 & \pm 7.33 & & $<0.001$ \\
\hline $\mathrm{CCl}$ score & 5.76 & \pm 4.02 & & 5.55 & \pm 4.11 & & 6.29 & \pm 3.86 & & 6.23 & \pm 2.98 & & 0.26 \\
\hline Depression & 169 & & 42 & 120 & & $4 I$ & 41 & & $4 I$ & 8 & & 62 & 0.34 \\
\hline
\end{tabular}

Note: aBased on diagnosis codes from medical records.

Abbreviations: 25(OH)D, total serum 25-hydroxyvitamin D; CCl, Charlson Comorbidity Index; ERA, Elder Risk Assessment. 
frequent depression $(P=0.024)$. This trend was not observed in males, likely due to only eight observed with severe deficiency. Both females and males were similar in age and frequency of depression; however, the females had a lower mean ERA $(6.05 \pm 6.37$ vs $7.89 \pm 6.63, P<0.001)$ and CCI $(3.54 \pm 3.50$ vs $5.76 \pm 4.02, P<0.001)$ scores than males.

\section{Relationship between vitamin D levels and age, depression, and frailty}

Contrasting the groups with and without a depression diagnosis, $25(\mathrm{OH}) \mathrm{D}$ was lower in the depression group compared with the usual care group $(32.7 \pm 13.5$ vs $35.0 \pm 15.4$, respectively, two sample $t$-test, $P=0.002$ ). After categorizing the groups into optimal, mild-moderate, and severe deficiency based on 25(OH)D levels, the severe deficiency group had more frequent depression diagnosis than the mild-moderate deficiency and optimal range groups (64\% vs $45 \%$ vs $42 \%$, respectively, Chi-square test, $P=0.013$ ). However, there was no difference in frequency of depression diagnosis between the mild-moderate deficiency and optimal range groups (45\% vs $42 \%$, respectively, Chi-square test, $P=0.40$ ). The same distribution was noted for females, with similar percentages. In males, the result was not significant due to a smaller number of males (405), with only 169 total cases of depression.

Patients with severe deficiency were older than those with optimal levels (two sample $t$-test, $P=0.012$ ). Correlation analyses (Table 2 ) showed that $25(\mathrm{OH}) \mathrm{D}$ was negatively correlated with age $(\mathrm{r}=-0.070, P=0.005)$, ERA score ( $\mathrm{r}=-0.113, P<0.0001)$, and CCI score $(\mathrm{r}=-0.101$, $P<0.0001)$. The univariate and multivariate logistic model with a clinical diagnosis of depression was performed using age, male gender, ERA score, vitamin D level, and CCI score as predictors in the model (Table 3 ).

Using univariate analysis, male gender was the only variable that did not predict depression, while all the other variables predicted depression including age, ERA score, vitamin D level, and CCI score. We then performed a multivariate analysis; however, we excluded the CCI score variable because the ERA score demonstrated a more dominant effect in predicting depression. In the multivariate analysis, neither age nor male gender predicted depression. What correlated with depression was a lower $25(\mathrm{OH}) \mathrm{D}$ level $(\mathrm{OR}=0.990$ and 95\% CI 0.983-0.998, $P=0.012)$ after adjustment for age, gender, and ERA score. The group with severe vitamin D deficiency was more likely to have depression $(\mathrm{OR}=2.093$ and $95 \%$ CI 1.092-4.011, $P=0.026)$.

\section{Discussion}

Our retrospective cross-sectional study describes the distribution of vitamin D levels among geriatric patients seen in the primary care setting, and reports significant associations between vitamin $\mathrm{D}$, age, gender, frailty, and medical burden.

We found a relationship between severe vitamin D deficiency and depression $(\mathrm{OR}=2.45$ and $95 \%$ CI $1.29-4.64$, $P=0.006)$ after adjustment for age and comorbid health conditions. Using continuous vitamin D levels, we further found a significant relationship between increasing vitamin $\mathrm{D}$ levels and decreased depression. These adjusted findings potentially indicate an ongoing relationship between vitamin D and depression. A previous study has shown some questions about the relationship of vitamin D to depression. ${ }^{23}$ Vitamin D trials have typically been small. In a trial of 44 people with seasonal affective disorder, there was some minimal evidence that vitamin D provided help with general well-being. ${ }^{24}$ In a trial of annual vitamin D supplementation in adults over 70 , there was no difference in mood or well-being in the group receiving vitamin $\mathrm{D}$ compared with placebo. ${ }^{25}$ In a group of 441 overweight adults, there seemed to be a clear relationship between vitamin D levels and depressive symptoms and also with improvement of depressive symptoms after treatment. ${ }^{17}$ Our study provides more evidence to answer this question and clearly indicates a relationship between clinical depression and vitamin D levels. This study is unique because it encompasses a broad population in a primary care practice in a northern latitude. Interestingly, $81 \%$ of the population had optimal levels of vitamin D.

Table 2 Pearson correlation coefficient analyses

\begin{tabular}{|c|c|c|c|c|c|c|}
\hline & \multicolumn{2}{|l|}{ Age } & \multicolumn{2}{|c|}{ ERA score } & \multicolumn{2}{|l|}{ CCI score } \\
\hline & Cor coef & $P$-value & Cor coef & $P$-value & Cor coef & $P$-value \\
\hline All 25(OH)D & -0.070 & 0.0050 & -0.113 & $<0.000 \mathrm{I}$ & -0.101 & $<0.000$ I \\
\hline Females $25(\mathrm{OH}) \mathrm{D}$ & -0.063 & 0.0289 & -0.074 & 0.0097 & -0.068 & 0.0172 \\
\hline Males 25(OH)D & -0.095 & 0.0573 & -0.203 & $<0.0001$ & -0.107 & 0.0310 \\
\hline
\end{tabular}

Abbreviations: 25(OH)D, total serum 25-hydroxyvitamin D; CCl, Charlson Comorbidity Index; Cor coef, Pearson Correlation Coefficient; ERA, Elder Risk Assessment. 
Table 3 Logistic model to predict depression

\begin{tabular}{|c|c|c|c|c|}
\hline \multirow[t]{2}{*}{ Standard parameter } & \multirow{2}{*}{$\begin{array}{l}\text { Odds } \\
\text { ratio }\end{array}$} & \multicolumn{2}{|l|}{$95 \% \mathrm{Cl}$} & \multirow[t]{2}{*}{$P$-value } \\
\hline & & Lower & Upper & \\
\hline \multicolumn{5}{|c|}{ Univariate analysis to predict depression } \\
\hline Age & 1.018 & 1.006 & 1.029 & 0.0035 \\
\hline Male & 0.939 & 0.747 & 1.179 & 0.5855 \\
\hline ERA score & 1.053 & 1.037 & 1.069 & $<0.0001$ \\
\hline $25(\mathrm{OH}) \mathrm{D}$ level & 0.988 & 0.980 & 0.995 & 0.0018 \\
\hline $\mathrm{CCl}$ score & 1.110 & 1.080 & 1.141 & $<0.0001$ \\
\hline \multicolumn{5}{|c|}{ Multivariate model using continuous vitamin $D$} \\
\hline Age & 1.000 & 0.987 & 1.013 & 0.9647 \\
\hline Male & 0.824 & 0.651 & 1.042 & 0.1066 \\
\hline ERA score & 1.052 & 1.035 & 1.070 & $<0.0001$ \\
\hline 25(OH)D level & 0.990 & 0.983 & 0.998 & 0.0118 \\
\hline \multicolumn{5}{|c|}{ Multivariate model with categories of vitamin $D$} \\
\hline Age & 1.000 & 0.987 & 1.013 & 0.9927 \\
\hline Male & 0.847 & 0.671 & 1.070 & 0.1648 \\
\hline ERA score & 1.053 & 1.036 & $1.07 \mid$ & $<0.0001$ \\
\hline $\begin{array}{l}\text { Severe } 25(\mathrm{OH}) \mathrm{D} \\
\text { deficiency }\end{array}$ & 2.093 & 1.092 & 4.011 & 0.0260 \\
\hline
\end{tabular}

Abbreviations: $25(\mathrm{OH}) \mathrm{D}$, total serum 25-hydroxyvitamin $\mathrm{D} ; \mathrm{CCl}$, Charlson Comorbidity Index; ERA, Elder Risk Assessment.

We found that frailty as defined by a high ERA score was associated with a low vitamin $\mathrm{D}$ level with a $P$-value $<0.001$. Data from the Third National Health and Nutrition Survey demonstrated a 3.7-fold increase in frailty among those with low vitamin D. ${ }^{26}$ Thus, adults who are frail are likely to be at a higher risk of vitamin D deficiency. This may be a result of less sun exposure or nutritional issues that can be associated with decreasing functional status. The effects of vitamin D and osteoporosis and bone health are fairly well established; thus, these individuals may be at a higher risk of fracture. Frailty encompasses fatigue and sarcopenia. Vitamin D may play a role in improving muscle performance in individuals with frailty. ${ }^{27}$ The effect of supplemental treatment of vitamin $\mathrm{D}$ for individuals beyond deficiency is unclear. ${ }^{28}$ Thus, our findings would be consistent with previous findings and reinforce the importance of vitamin D when considering frailty. It also reinforces the importance of evaluating vitamin D levels in individuals who are identified as frail by any mechanism.

\section{Study limitations}

Our sample consisted of community dwelling individuals in a medium-sized city in the upper Midwest, and our findings may not be generalizable to other geographic areas with increased sun exposure. Rochester, Minnesota, and Olmsted County have a largely Northern European population (85\%); thus, regions with different racial or ethnic groups may have different findings. Despite these potential differences, the general conclusion that low vitamin D levels can influence depression is still likely valid. The electronic method of collecting administrative data for depression and frailty does not apply to more rigorous methods of further confirming and characterizing these conditions. Both conditions have accepted criteria for a clinical diagnosis. However, these methods do confirm their presence as noted by the clinician and have been found to be of utility, especially when looking at big cohorts. Ideally, depression would be confirmed using Diagnostic and Statistical Manual of Mental Disorders (DSM) IV criteria; however, practically speaking, most primary care practices make the diagnosis on clinical grounds and the application of these findings to clinical practice could potentially favor vitamin D evaluation. A further limitation is the development of the cohort. Because only patients with a vitamin D level were included, there is a potential bias for symptomatic patients with low vitamin D level, compared to the general population. Lastly, the lack of data on seasonality limits our ability to determine differences in vitamin D levels by season, although a previous study of psychiatric inpatients found no association between vitamin D level and the season of testing. ${ }^{29}$

Despite the limitations, our study sample is large and represents the typical primary care geriatric patient in our community. This study provides further insight into the rates of vitamin D deficiency and further evidence of its association with depression.

In summary, a fifth of our sample of geriatric patients in primary care had vitamin D deficiency, and those with vitamin $\mathrm{D}$ deficiency were older and more likely to have depression.

\section{Acknowledgments}

No funding sources to acknowledge. This study was a poster presentation at the Second Annual Mayo Clinic Robert and Arlene Kogod Center on Aging Conference in Groningen, Netherlands, October 2011.

\section{Disclosure}

The authors report no conflicts of interest in this work.

\section{References}

1. Holick MF. High prevalence of vitamin D inadequacy and implications for health. Mayo Clin Proc. 2006;81:353-373.

2. Holick MF. Vitamin D deficiency. N Engl J Med. 2007;357:266-281.

3. Muir SW, Montero-Odasso M. Effect of vitamin D supplementation on muscle strength, gait and balance in older adults: a systematic review and meta-analysis. J Am Geriatr Soc. 2011;59:2291-2300.

4. Ross AC, Manson JE, Abrams SA, et al. The 2011 report on dietary reference intakes for calcium and vitamin D from the Institute of Medicine: what clinicians need to know. J Clin Endocrinol Metab. 2011; 96:53-58. 
5. Holick MF, Binkley NC, Bischoff-Ferrari HA, et al. Evaluation, treatment, and prevention of vitamin D deficiency: an Endocrine Society clinical practice guideline. J Clin Endocrinol Metab. 2011;96: 1911-1930.

6. Kennel KA, Drake MT, Hurley DL. Vitamin D deficiency in adults: when to test and how to treat. Mayo Clin Proc. 2010;85:752-757; quiz 757-758.

7. Berk M, Jacka FN, Williams LJ, Ng F, Dodd S, Pasco JA. Is this $\mathrm{D}$ vitamin to worry about? Vitamin $\mathrm{D}$ insufficiency in an inpatient sample. Aust N Z J Psychiatry. 2008;42:874-878.

8. Thomas MK, Lloyd-Jones DM, Thadhani RI, et al. Hypovitaminosis D in medical inpatients. N Engl J Med. 1998;338:777-783.

9. Chatfield SM, Brand C, Ebeling PR, Russell DM. Vitamin D deficiency in general medical inpatients in summer and winter. Intern Med J. 2007;37:377-382.

10. Barnard K, Colon-Emeric C. Extraskeletal effects of vitamin D in older adults: cardiovascular disease, mortality, mood, and cognition. Am J Geriatr Pharmacother. 2010;8:4-33.

11. Hoogendijk WJ, Lips P, Dik MG, Deeg DJ, Beekman AT, Penninx BW. Depression is associated with decreased 25-hydroxyvitamin D and increased parathyroid hormone levels in older adults. Arch Gen Psychiatry. 2008;65:508-512.

12. Milaneschi Y, Shardell M, Corsi AM, et al. Serum 25-hydroxyvitamin D and depressive symptoms in older women and men. J Clin Endocrinol Metab. 2010;95:3225-3233.

13. Stewart R, Hirani V. Relationship between vitamin D levels and depressive symptoms in older residents from a national survey population. Psychosom Med. 2010;72:608-612.

14. Wilkins CH, Sheline YI, Roe CM, Birge SJ, Morris JC. Vitamin D deficiency is associated with low mood and worse cognitive performance in older adults. Am J Geriatr Psychiatry. 2006;14:1032-1040.

15. Zhao G, Ford ES, Li C, Balluz LS. No associations between serum concentrations of 25-hydroxyvitamin $\mathrm{D}$ and parathyroid hormone and depression among US adults. Br J Nutr. 2010;104:1696-1702.

16. Schneider B, Weber B, Frensch A, Stein J, Fritz J. Vitamin D in schizophrenia, major depression and alcoholism. J Neural Transm. 2000;107:839-842.

17. Jorde R, Sneve M, Figenschau Y, Svartberg J, Waterloo K. Effects of vitamin D supplementation on symptoms of depression in overweight and obese subjects: randomized double blind trial. $J$ Intern Med. 2008;264:599-609.
18. St Sauver J, James B, Rademacher D, et al. Comparison of Mayo Clinic Coding Systems. Rochester, Minnesota: Department of Health Sciences Research, Mayo Clinic, 2010:1-26. Available from: http:// mayoresearch.mayo.edu/mayo/research/biostat/upload/83.pdf. Accessed March 4, 2013.

19. Crane SJ, Tung EE, Hanson GJ, Cha S, Chaudhry R, Takahashi PY. Use of an electronic administrative database to identify older community dwelling adults at high-risk for hospitalization or emergency department visits: the elders risk assessment index. BMC Health Serv Res. 2010;10:338.

20. Takahashi PY, Tung EE, Crane SJ, Chaudhry R, Cha S, Hanson GJ. Use of the elderly risk assessment (ERA) index to predict 2-year mortality and nursing home placement among community dwelling older adults. Arch Gerontol Geriatr. 2012;54:34-38.

21. Charlson ME, Pompei P, Ales KL, MacKenzie CR. A new method of classifying prognostic comorbidity in longitudinal studies: development and validation. J Chronic Dis. 1987;40:373-383.

22. de Groot V, Beckerman H, Lankhorst GJ, Bouter LM. How to measure comorbidity: a critical review of available methods. J Clin Epidemiol. 2003;56:221-229.

23. Parker G, Brotchie H. 'D' for depression: any role for vitamin D? 'Food for Thought' II. Acta Psychiatr Scand. 2011;124:243-249.

24. Lansdowne AT, Provost SC. Vitamin D3 enhances mood in healthy subjects during winter. Psychopharmacology (Berl). 1998;135: 319-323.

25. Sanders KM, Stuart AL, Williamson EJ, et al. Annual high-dose vitamin D3 and mental well-being: randomised controlled trial. Br J Psychiatry. 2011;198:357-364.

26. Wilhelm-Leen ER, Hall YN, Deboer IH, Chertow GM. Vitamin D deficiency and frailty in older Americans. J Intern Med. 2010;268: $171-180$.

27. Montero-Odasso M, Duque G. Vitamin D in the aging musculoskeletal system: an authentic strength preserving hormone. Mol Aspects Med. 2005;26:203-219.

28. Millward DJ. Nutrition and sarcopenia: evidence for an interaction. Proc Nutr Soc. 2012;71:566-575.

29. Lapid MI, Drake MT, Geske JR, et al. Hypovitaminosis D in psychogeriatric inpatients. J Nutr Health Aging. September 1-4, 2012 .
Clinical Interventions in Aging

\section{Publish your work in this journal}

Clinical Interventions in Aging is an international, peer-reviewed journal focusing on evidence-based reports on the value or lack thereof of treatments intended to prevent or delay the onset of maladaptive correlates of aging in human beings. This journal is indexed on PubMed Central, MedLine, the American Chemical Society's 'Chemical Abstracts

\section{Dovepress}

Service' (CAS), Scopus and the Elsevier Bibliographic databases. The manuscript management system is completely online and includes a very quick and fair peer-review system, which is all easy to use. Visit http://www.dovepress.com/testimonials.php to read real quotes from published authors. 